\title{
Frequency of fetal iron deficiency anemia at the time of birth in obese mothers.
}

\author{
1. MBBS, FCPS \\ Assistant Professor Obstetrics \& \\ Gynecology \\ Nishtar Medical University, Multan. \\ 2. MBBS, FCPS \\ Associate Professor Obstetrics \& \\ Gynecology \\ Nishtar Medical University, Multan. \\ 3. MBBS, FCPS \\ Assistant Professor Obstetrics \& \\ Gynecology \\ Nishtar Medical University, Multan. \\ 4. MBBS, FCPS \\ Associate Professor Obstetrics \& \\ Gynecology \\ Nishtar Medical University, Multan. \\ 5. MBBS, FCPS \\ Senior Registrar Obstetrics \& \\ Gynecology \\ Nishtar Medical University, Multan. \\ Correspondence Address: \\ Dr. Amna Aziz \\ Department of Obstetrics \& \\ Gynecology \\ Nishtar Medical University, Multan. \\ dramna14@gmail.com \\ Article received on: \\ 04/11/2019 \\ Accepted for publication: \\ 05/03/2020
}

\begin{abstract}
Amna Aziz' ${ }^{1}$, Hajra Sultana ${ }^{2}$, Saima Qadir ${ }^{3}$, Saima Ashraf ${ }^{4}$, Muhammad Sajjad Masood ${ }^{5}$
ABSTRACT... Objectives: To determine frequency of fetal iron deficiency anemia at the time of birth in obese mothers. Study Design: Cross-sectional Descriptive study. Setting: Department of Obstetrics and Gynecology, Nishtar Hospital Multan. Period: September 2018 to February 2019. Material \& Methods: A total of 368 obese pregnant women with singleton pregnancy between $37-40$ weeks of gestation were included in the study after informed consent. Cord blood was collected after delivery via syringe aspiration from the umbilical vein. Fetal Iron status in the form of serum iron, hemoglobin, transferrin saturation was measured with calorimetric endpoint assay. Obesity in pregnancy is defined as BMI equal and more than $30 \mathrm{~kg} / \mathrm{m}^{2}$. Fetal iron deficiency anemia was defined as fetal hemoglobin less than $14.5 \mathrm{~g} / \mathrm{dl}$, fetal iron 97.3 micro gram/dl and transferrin saturation $39.6 \%$ at birth. Results: Among 368 cases, $87.8 \%$ of cases were having their BMI $30 \mathrm{~kg} / \mathrm{m}^{2}$ to $34.9 \mathrm{~kg} / \mathrm{m}^{2}$. BMI between $35 \mathrm{~kg} / \mathrm{m}^{2}$ to $39.9 \mathrm{~kg} / \mathrm{m}^{2}$ was noted in $10 \%$ of cases and in $2.2 \%$ of cases BMl was equal to or more than $40 \mathrm{~kg} / \mathrm{m}^{2}$. Frequency of neonatal iron deficiency anemia was $22.8 \%$. Conclusion: There is a increase prevalence of obesity in women of childbearing age however maternal obesity has no significant correlation of fetal iron deficiency anemia.
\end{abstract}

Key words: $\quad$ BMI, Fetal Anemia, Maternal Obesity.

Article Citation: Aziz A, Sultana H, Qadir S, Ashraf S, Masood MS. Frequency of fetal iron deficiency anemia at the time of birth in obese mothers. Professional Med J 2021; 28(7):973-977. https://doi.org/10.29309/TPMJ/2021.28.07.4316

\section{INTRODUCTION}

Obesity is the most common disorder in developed world. ${ }^{1}$ It is defined as increase in body mass index (BMI) of more than $30 \mathrm{~kg} / \mathrm{m}^{2}$. Moreover, it is further classified into three main classes: Class I $\left(30-34.9 \mathrm{~kg} / \mathrm{m}^{2}\right)$, Class II (35$39.9 \mathrm{~kg} / \mathrm{m}^{2}$ ), and Class III (greater than $40 \mathrm{~kg} / \mathrm{m}^{2}$ ). In recent past, obesity has significantly outburst in the developing world. ${ }^{2}$ Frequency of obesity in pregnancy has enormously increased in last decade. It is reported to be more than $30 \%$ in Europe. $^{3}$

Maternal obesity is associated with many adverse pregnancy outcomes including higher risk of maternal hypertension, gestational diabetes, difficult delivery, increased caesarean section rate and postpartum hemorrhage. ${ }^{4}$ There is an increased risk of gross congenital defects, neural tube defects, large for gestational age babies, macrosomia, neonatal anemia and low apgar score in babies born to obese mothers. ${ }^{5}$ It is indicated in recent studies that maternal obesity is also associated with childhood obesity, adverse neuro developmental outcomes like cerebral palsy, lower cognitive capabilities, autism, attention deficit hyperactivity disorder and developmental delay. ${ }^{6}$

Obesity is actually a state of low grade chronic inflammation. ${ }^{7}$ Many inflammatory mediators are elevated in obesity like interleukin-6. It induces the expression of hepcidin. ${ }^{8}$ It is an important regulator of iron homeostasis and it binds to the iron exporter; ferroportin on gut epithelium and surface of macrophages thus inhibiting iron trasnport. ${ }^{9}$ Hepcidin correlates with low iron status in the obese mothers. ${ }^{10}$ Hepcidin is expressed at a lowest level during pregnancy in order to provide maximum iron transfer to the fetus. ${ }^{11,12}$ In obese mothers fetal iron transfer is decreased due to excessive hepcidin so 
increase prevalence of iron deficiency anemia in newborns. ${ }^{13}$

There is scarce data regarding actual effect of maternal obesity on fetal iron deficiency anemia. A study done in the United States of America indicated that fetal anemia is more common in mothers with BMI $35 \mathrm{~kg} / \mathrm{m}^{2} .{ }^{14}$ In contrast to this, another study done in USA showed no impact of gestational weight gain and obesity on neonatal iron deficiency anemia. ${ }^{15}$ In a Californian study, fetal iron status was adversely affected by maternal obesity. Transferrin saturation has also been shown to be reduced up to $39.6 \%$ in this study. ${ }^{16}$ A study conducted in china in 2016 also showed negative association between maternal obesity and neonatal iron status. ${ }^{5}$ Same effect is seen in the data from a prospective maternalinfant birth cohort in ireland. ${ }^{17}$

In Pakistan, very limited data regarding obesity in pregnancy related to fetal iron deficiency anemia is available. Data from national health survey of Pakistan showed prevalence of obesity in reproductive age was reported $14 \%$ in women from rural areas while $37 \%$ from urban areas. ${ }^{10}$

The results of this study could find correlation of maternal obesity and fetal iron deficiency anemia. The evidence from our study could help to devise interventional strategies to alleviate the potential adverse consequence of obesity in pregnancy on newborns.

\section{MATERIAL \& METHODS}

Study was conducted in the Department of Obstetrics and Gynecology, Nishtar Hospital Multan from September 2018 to February 2019. It was a Cross-sectional descriptive study. Non probability consecutive sampling was used. A total of 368 pregnant women aged 20-40 years were included in the study after informed consent. Both prim gravidas or multigravidas (up to 3), between 37-40 weeks of pregnancy were included. All women were having singleton pregnancy and Body Mass Index $30 \mathrm{~kg} / \mathrm{m}^{2}$ or more. Cord blood was collected after delivery via syringe aspiration from the umbilical vein. Hemoglobin, serum iron, transferrin saturation were measured with calorimetric endpoint assay in Central Laboratory of Nishtar Hospital, Multan, to access fetal iron deficiency anemia The data was entered and analyzed by using computer software SPSS version18. Mean and SD was calculated for quantitative variables like age, gestational age of patient. Frequencies and percentages were calculated for categorical variables like fetal anemia, BMI and weight of baby. Effect modifiers like mode of delivery, age, gestational age and parity was controlled by stratification.

\section{RESULTS}

Among 368 patients, 323 were having their BMI $30 \mathrm{~kg} / \mathrm{m}^{2}$ to $34.9 \mathrm{~kg} / \mathrm{m}^{2}$. BMI between $35 \mathrm{~kg} / \mathrm{m}^{2}$ to $39.9 \mathrm{~kg} / \mathrm{m}^{2}$ was noted in 27 cases and in 8 of cases $\mathrm{BMI}$ was equal to or more than 40 . Demographic findings in terms of age, parity and duration of gestation shown in Table-I Neonatal anemia was analyzed in 368 samples. It was found in 84 cases and in 284 cases, no neonatal anemia was observed at the time of delivery (Table-II). Among 368 cases, majority of the babies were having their birth weight less than $4000 \mathrm{gm}$ i.e. $75.82 \%$ of babies. Birth weight equal to or more than 4000 gm was recorded in $24.18 \%$ of babies (Figure-1).

\begin{tabular}{|l|c|c|}
\hline \multicolumn{1}{|c|}{ Age in years } & Number of cases & Percentage \\
\hline $20-30$ & 163 & 44.3 \\
\hline $31-40$ & 205 & 55.7 \\
\hline Total & 368 & 100 \\
\hline Parity & Number of cases & Percentage \\
\hline P1 & 71 & 19.29 \\
\hline P2 & 118 & 32.07 \\
\hline P3 & 179 & 48.64 \\
\hline Total & 368 & 100 \\
\hline Gestational age & Number of cases & Percentage \\
\hline $37-38$ weeks & 154 & 41.85 \\
\hline $39-40$ weeks & 214 & 58.15 \\
\hline Total & 368 & 100 \\
\hline BMI & Number of cases & Percentage \\
\hline $30-34.9$ & 37 & 87.8 \\
\hline $35-39.9$ & 8 & 10.0 \\
\hline$\geq 40$ & 368 & 2.2 \\
\hline Total & Table-l. Demographic features. (n=368) \\
\hline
\end{tabular}




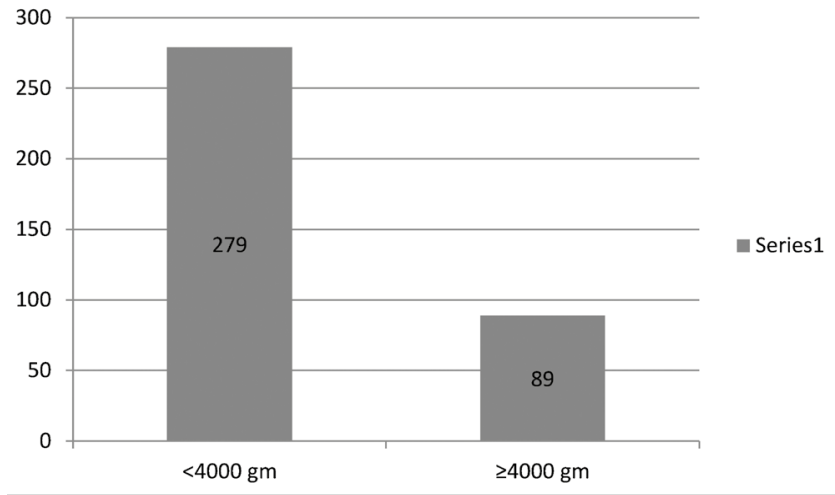

Figure-1. Weight of the neonates. $(n=368)$.

Majority of the babies were having their birth weight less than $4000 \mathrm{gm}$ i.e. $75.82 \%$ of babies.

\begin{tabular}{|l|c|c|}
\hline \multicolumn{1}{|c|}{\begin{tabular}{c} 
Fetal \\
\multicolumn{1}{|c|}{$\begin{array}{c}\text { Iron Deficiency } \\
\text { Anemia }\end{array}$}
\end{tabular}} & $\begin{array}{c}\text { Number of } \\
\text { Cases }\end{array}$ & Percentage \\
\hline $\begin{array}{l}\text { Present } \\
\text { (hemoglobin }<14.5 \mathrm{~g} / \mathrm{dl} \text { ) } \\
\text { (transferrin saturation }\end{array}$ & 84 & 22.83 \\
$\begin{array}{l}39.6 \% \text { or less) } \\
\text { Absent } \\
\text { (hemoglobin }>14.5 \mathrm{~g} / \mathrm{dl} \text { ) } \\
\text { (Trasferrin saturation } \\
>39.6 \%)\end{array}$ & 284 & 77.17 \\
\hline Total & 368 & 100 \\
\hline
\end{tabular}

Table-II. Frequency of fetal Iron deficiency anemia. $(n=368)$

Frequency of fetal iron deficiency anemia was $22.83 \%$.

\begin{tabular}{|c|c|c|c|}
\hline Age & $\begin{array}{l}\text { Fetal } \\
\text { Anaemia } \\
\text { Yes }\end{array}$ & $\begin{array}{c}\text { Fetal } \\
\text { Anaemia } \\
\text { No }\end{array}$ & P-Value \\
\hline $20-30$ & 37 & 126 & \multirow{2}{*}{$\begin{array}{c}\text { Chi-square value }=0.0026 \\
\text { d.f. }=1 \\
\text { p value }=0.9588\end{array}$} \\
\hline $31-40$ & 47 & 158 & \\
\hline \multicolumn{4}{|l|}{ Parity } \\
\hline P1 & 16 & 55 & \multirow{3}{*}{$\begin{array}{c}\text { Chi-square value }=0.2242 \\
\text { d.f. }=2 \\
\text { p value }=0.9978\end{array}$} \\
\hline $\mathrm{P} 2$ & 27 & 91 & \\
\hline P3 & 41 & 138 & \\
\hline \multicolumn{4}{|c|}{ Gestational age } \\
\hline $\begin{array}{l}37-38 \\
\text { weeks }\end{array}$ & 35 & 119 & \multirow{2}{*}{$\begin{array}{c}\text { Chi-square value }=0.00146 \\
\text { d.f. }=1 \\
\text { p value }=0.9694\end{array}$} \\
\hline $\begin{array}{l}39-40 \\
\text { weeks }\end{array}$ & 49 & 165 & \\
\hline \multicolumn{4}{|l|}{ BMI } \\
\hline $30-34.9$ & 74 & 249 & \multirow{3}{*}{$\begin{array}{c}\text { Chi-square value }=0.0532 \\
\text { d.f. }=2 \\
\text { p value }=0.9737\end{array}$} \\
\hline $35-39.9$ & 8 & 29 & \\
\hline$\geq 40$ & 2 & 6 & \\
\hline
\end{tabular}

Table-III. Association of Fetal Iron deficiency Anemia with demographic features. $(n=368)$

\section{DISCUSSION}

According to WHO obesity is one of the most blatantly visible and most neglected, public health problems and it is a killer disease at par with HIV and malnutrition. It may result in a decrease in life expectancy in the future. ${ }^{18}$ Prevalence of obesity is more in women than men making it a point of serious concern for obstetrician. ${ }^{19}$

In our study, neonatal anemia was a finding in $22.83 \%$ of cases at the time of delivery. While in another study done in America, anemia was found in $24 \%$ neonates of obese mothers. ${ }^{15}$ The results of our study were comparable with the results of another International study in India in which prevalence of anemia in the $\mathrm{BMI}>30 \mathrm{~kg} / \mathrm{m}^{2}$ group was $16 \% .^{20}$ The difference was statistically insignificant with a $p$ value of $0.444 .^{20}$ Our results were comparable with the results of another study done in Spain where increased maternal BMI was having no significant effect on any of the hematological parameters of newborn. ${ }^{13}$ The results generated by our study did not correspond with the results of another study in which frequency of fetal anemia was $39.6 \%$ in obese mothers. ${ }^{16}$ Our results were also in contrast with another large cohort study done in china that was showing that increase maternal BMI was linked with infant anemia at 6 months (adjusted OR1.39,95\%Cl 1.02,1.88). ${ }^{21}$ In a study done in china, $33 \%$ of neonates born to obese mothers had low serum ferritin and iron deficiency anemia. ${ }^{5}$ Another study done in New York showed that serum ferritin was lowered by $29 \%$ in infants of obese mothers. ${ }^{22}$ They also found that association between pre pregnancy body mass index and fetal anemia was more pronounced in male babies. ${ }^{22}$

In our study, among 368 cases, $55.70 \%$ were in age group 31 to 40 years and $44.3 \%$ of cases were in age group 20-30 years. The results generated by our study are comparable with another study in India. ${ }^{20}$ In that study, $48 \%$ of the BMI greater than 30 category women was reported in more 26 years of age, but $28 \%$ of the BMI more than 30 group was reported in the $<26$ years category. The $p$ value was 0.039 and it was statistically significant. ${ }^{20}$ Our results were also comparable with another study 
in Saudi Arabia, who reported that average age of obese patients was 25.2 years and that of nonobese was 24.1years, concluding that obesity was more common in women of higher age. ${ }^{23}$

Our study has some limitations that include relatively small size of sample and lack of data regarding pre pregnancy body mass index. Moreover we did not collect data about iron intake of obese pregnant women. We did not measure serum ferritin in cord blood sample which is more sensitive to rule out iron deficiency anemia.

\section{CONCLUSION}

Neonatal anemia was finding in about one third of cases in our study although a non-significant correlation is found with maternal obesity. More insight is needed regarding iron studies in cord blood to estimate the exact correlation between iron deficiency anemia in newborn and obese mothers.

There is increase prevalence of obesity in women of childbearing age and this finding is of prime importance for obstetricians. Maternal obesity has negative influence on fetal health so prepregnancy counseling is very important regarding detrimental effects associated with obesity.

Copyright@ 05 Mar, 2020.

\section{REFERENCES}

1. Shabab U, Tahir S. Effect of obesity on cesarean section rate. J surg pak (int).2010; 15:92-6.

2. Fallatah Am, Babatin $\mathrm{Hm}$, Nassibi $\mathrm{Km}$, Banweer Mk, et al. Maternal and neonatal outcomes among obese pregnant women in king abdul aziz university hospital: A retrospective single-center medical record review. Med arch. 2019; 73:425-432.

3. Simko M., Totka A., Vondrova D, et al. Maternal body mass index and gestational weight gain and their association with pregnancy complications and perinatal conditions. Int $\mathrm{j}$ environ res public health. 2019; 16:1751.

4. Poston L, Caleyachetty R, Cnattingius S, et al. Pre conceptional and maternal obesity: Epidemiology and health consequence. Lancet diabetes endoc. 2016; 4:1025-1036.
5. Jones Ad, Zhao G, Jiang Yp, et al. Maternal obesity during pregnancy is negatively associated with maternal and neonatal iron status. Eur j clin nutr. 2016; 70:918-924.

6. Neri C, Edlow Ag. Effects of maternal obesity on fetal programming: Molecular approaches. Cold spring harb perspect med. 2015; 6(2):a026591.

7. Catalano Pm, Shankar K, Obesity and pregnancy: Mechanism of short term and long term adverse consequences for mother and child. BMJ. 2017; 356:j1.

8. Flynn Ac, Begum S, White SI, et al. Relationships between maternal obesity and maternal and neonatal iron status. Nutrients. 2018; 10(8):1000.

9. Rahma H, Lumbanraja Sn, Lubis Z, et al. Hepcidin and ferritin in obese pregnant women and normal body mass index before pregnancy. Med j indones.2018; 3:22-26.

10. Fatima S, Mehmood S, Taj N. Frequency of cesarean section in women with increased body mass index. Rawal medical journal pak. 2014; 39(1):45-7.

11. Hedengran Kk, Nelson D, Andersen Mr, Stender S, et al. Hepcidin levels are low during pregnancy and increase around delivery in women without iron deficiency- a prospective cohort study. J matern fetal neonatal med.2016; 29:1506-1508.

12. Kulik-Rechberger B, Kosciesza A, Szponar E, Domosud $\mathrm{J}$. Hepcidin and iron status in pregnant women and full-term newborns in first days of life. Ginekol pol. 2016; 87:288-292.

13. Garcia-Valdes L, Campoy C, Hayes H, et al. The impact of maternal obesity on iron status, placental transferrin receptor expression and hepcidin expression in human pregnancy. Int j obes (lond). 2015; 39:571-578.

14. Dosch N C, Guslits Ef, Weber Mb, et al. Maternal obesity affects inflammatory and iron indices in umbilical cord blood. J pediatr. 2016; 172:20-28.

15. Cao C, Pressman Ek, Cooper Em, et al. Pre pregnancy body mass index and gestational weight gain has no negative impact on maternal and neonatal iron status. Reprod sci.2016; 23:613-622.

16. Carlota Dao M, Sen S, Lyer C, et al. Obesity during pregnancy and fetal iron status: Is hepcidin the link? .j perinatol. 2013; 33(3):177-81. 
17. Mccarthy E, Kenny L, Hourihane J, et al. Impact of maternal, antenatal and birth-associated factors on iron stores at birth: Data from a prospective maternal-infant birth cohort. Eur j clinc nutr. 2017; 71:782-787.

18. Haslam Dw, James Wp. Obesity. Lancet 2005; 366:1197-1209.

19. Ballesta-Castillejos A, Gómez-Salgado J, RodríguezAlmagro J, Ortiz-Esquinas I, Hernández-Martínez A. Relationship between maternal body mass index and obstetric and perinatal complications. Journal of clinical medicine. 2020; 9(3):707.
20 Pal SI, Aggarwal A, Kaur G. To assess the effect of maternal BMI on obstetrical outcome. International journal of advancements in research \& technology. 2012; 1:1-39.

21. Yin S, Zhou Y, Li H, et al. Association of maternal BMI during early pregnancy with infant anemia: A large Chinese birth cohort. Nutr metab (lond). 2020; 17:32.

22. Campbell Rk, Tamayo-Ortiz M, Cantoral A, et al. Maternal prenatal psychosocial stress and pre pregnancy $\mathrm{BMI}$ associations with fetal iron status. Curr dev nutr. 2020; 4(2):nzaa018.

23. Nisa Mu, Aslam M, Ahmed Sr, et al. Impact of obesity on fetomaternal outcome in pregnant Saudi females. Int. j health sci. 2009; 3(2):187-195.

\section{AUTHORSHIP AND CONTRIBUTION DECLARATION}

\begin{tabular}{c|l|l|} 
Sr. \# & Author(s) Full Name & \multicolumn{1}{|c|}{ Contribution to the paper } \\
\hline 1 & Amna Aziz & $\begin{array}{l}\text { Conceived, designed and did statistical } \\
\text { analysis and editing of manuscript. } \\
\text { Conceived, designed and did statistical } \\
\text { analysis and editing of manuscript. } \\
\text { Did review and final approval of } \\
\text { manuscript. }\end{array}$ \\
\hline 5 & Hajra Sultana & $\begin{array}{l}\text { Sid data collection and manuscript } \\
\text { writing. } \\
\text { Did data collection and manuscript } \\
\text { writing. }\end{array}$
\end{tabular}

